\title{
OS ESPAÇOS DE REPRESENTAÇÃO SEGUNDO A GEOGRAFIA CRÍTICA
}

\author{
Dayse Leite Pereira ${ }^{1}$ \\ José Queiroz de Miranda Neto ${ }^{2}$
}

\begin{abstract}
RESUMO
A Geografia é uma ciência plural e, devido a sua pluralidade, sofreu muitos conflitos no campo epistemológico e conceitual. Este fato reflete a sua evolução histórica, uma vez que essas discussões teóricas e mudanças conceituais se dão conforme a transformação da sociedade e revelam uma ciência atual e dinâmica que contribui de modo persistente à construção de um saber espacial. Partindo desse pressuposto, o presente artigo tem por objetivo discutir o espaço geográfico a partir dos espaços de representação, enfatizando os principais marcos da Geografia e a mudança do pensamento sobre o homem e o espaço sob uma perspectiva Lefbreviana, tendo como corrente de análise a Geografia Crítica. A partir de um estudo bibliográfico que se vale de diferentes autores da ciência geográfica e de outros campos do conhecimento, busca-se entender como a concepção que se tem do espaço contribui para uma nova forma de traçar caminhos e entender a realidade de maneira mais profunda, assim como a valorização da dimensão temporal permite compreender que o espaço, em todo e qualquer período histórico, resulta de um processo de produção que abarca diferentes facetas da existência humana.
\end{abstract}

Palavras-chave: Espaço Geográfico. Espaços de representação. Geografia crítica.

\section{SPACES OF REPRESENTATION ACCORDING TO CRITICAL GEOGRAPHY}

\begin{abstract}
Geography is a plural science and due to its plurality, it suffered many conflicts in the epistemological and conceptual field. This fact reflects its historical evolution, since these theoretical discussions and conceptual changes that take place according to the transformation of society, reveal a current and dynamic science that aims to contribute to the construction of spatial knowledge. Based on this assumption, the present article aims to discuss the geographical space from the representation spaces, emphasizing the main landmarks of geography and the change in thinking about man and space under a Lefbrevian perspective and having Geography as the current of analysis. Criticism. Based on a bibliographic study based on various authors from geography and other fields of knowledge, we seek to understand how the conception of space contributes to a new way of tracing paths and understanding reality in a more profound way, as well as the valorization of the temporal dimension in order to understand that the space in each and every historical period result from a production.
\end{abstract}

Keywords: Geographic space. Representation spaces. Critical geography.

Data de submissão: 21.01 .2021

Data de aprovação:03.02.2021

\section{INTRODUÇÃO}

A Ciência geográfica é um campo do conhecimento em constante evolução, sendo considerada uma ciência plural e marcada por mudanças em seus conceitos-chaves que são: espaço, lugar, paisagem, território e região. Considera-se, no presente artigo, o espaço

\footnotetext{
${ }^{1}$ Licenciatura Plena em Pedagogia pela UFPA, especialista em Educação Especial e Língua Brasileira de Sinais - LIBRAS pela Faculdade de Tecnologia Equipe Darwin (2013), e atualmente é mestranda do programa de pósgraduação em Geografia-PPGEO-UFPA. E-mail: dayseleite@ufpa.br

${ }^{2}$ Graduado e Mestre em Geografia pela UFPA, Doutor em Geografia pela FCT/UNESP. Professor assistente da UFPA e coordenador do Laboratório de Estudos Populacionais e Urbanos - LEPURB/UFPA. E-mail: mirandaneto@ufpa.br.
} 
enquanto análise da Geografia Crítica, que é a ciência marcada por uma análise marxista baseada nas relações de trabalho, relações sociais, desprendendo-se apenas de visões descritivas da realidade. A Geografia, tal qual outras ciências de cunho social, tem uma relação de afinidade com outras ciências, como por exemplo a Economia e a Sociologia, o que faz dela uma ciência que busca explicar a realidade a partir de diferentes enfoques teóricofilosóficos. O objetivo deste artigo é discorrer sobre os espaços de representação em uma abordagem lefrebvriana, demonstrando sua importância na ciência geográfica.

No que tange ao espaço enquanto categoria analítica, pode-se dizer que é um conceito complexo e de suma importância para a Geografia. Partindo dessa premissa, Carlos (2011, p.17) afirma que "o espaço, como categoria de pensamento e realidade prática, traz em si a ideia de referência para o ser humano, uma vez que é sua condição de existência, assim como as transformações da sociedade trazem como consequência modificações espaciais". Diante disso, percebe que a compreensão de espaço perpassa a sua materialidade, atingindo um viés subjetivo que é o das relações sociais. A Geografia Crítica vem trazer, portanto, essa discussão tendo como base o materialismo histórico e dialético.

O foco do debate é o entendimento dos espaços de representação, conceito desenvolvido por Lefebvre (1974) e que trouxe tanto para a Geografia como para a outras ciências uma forma de ver o espaço como conectado à sociedade na forma de representação do mundo, da vida e do cotidiano. Tal visão é importante pois não despreza a materialidade, mas entende que os símbolos e as formas mais subjetivas de construção social são componentes indivisíveis do espaço.

Os autores utilizados como aporte teórico desse artigo foram escolhidos com base na corrente da Geografia crítica, optando por autores de referência nessa temática, diversificando entre estrangeiros e brasileiros e buscando embasar a discussão conceitual de espaço, tais como Lefebvre (1976), Harvey (2006), Santos (1996; 2008), Lacoste (1990), Moreira (1985), Carlos (2011), Gottdiener (2010), Brunet (1990) e Castells (2000). Na primeira seção, faz-se um breve histórico sobre a Geografia Crítica, trazendo sua base teórica e surgimento, assim como o conceito de espaço geográfico de modo diversificado, conforme a teoria de autores contemporâneos. Na segunda seção, apresenta-se diferentes concepções a respeito dos espaços de representação.

\section{DA CRÍTICA DA GEOGRAFIA AOS ESPAÇOS DE REPRESENTAÇÃO}

A Geografia Crítica surgiu na França em meados da década de 1970, e em seguida espalhou-se por outros países como: Suíça, Itália, Alemanha, Brasil, México entre outros. Essa corrente da Geografia tem como base filosófica e teórica o materialismo histórico e dialético. Fundamentada em teorias marxistas, vai além do pensamento tradicional ligado fortemente ao positivismo lógico e ao empirismo, trazendo assim uma abordagem militante com foco em uma sociedade mais justa e igualitária.

Partindo desse pressuposto de renovação e construção de uma nova geografia, Corrêa (1982, p.20) diz:

\footnotetext{
A abertura política que se afirma no país, a descrença que vários geógrafos passaram a ter em relação à "nova geografia", a própria falência do sistema de planejamento, a acentuação dos problemas nacionais que se tinha proposto solucionar, a volta de Milton Santos com sua riqueza e vigor intelectual, tudo isto iria contribuir para a emergência de uma "geografia nova" não comprometida com o aparelho ideológico do Estado, comprometida sim, com os interesses da maioria da população, com os trabalhadores rurais e urbanos, e com um projeto histórico que é o da transformação da sociedade.
} 
Essa nova Geografia vem responder a uma necessidade da sociedade em romper com a neutralidade e assumir um viés político, reproduzindo o ideal marxista da luta de classes. Uma característica notória dessa corrente é a criticidade com que analisa o espaço geográfico, saindo do âmbito tradicional com foco no empirismo e "pensando o espaço em sua complexidade" (LACOSTE, 1990, p.35).

Esta ciência crítica surge em meio crise trazendo mudanças expressivas e respondendo a um descontentamento geral. Como afirma Moreira (1985, p.58), a Geografia é uma ciência de extrema relevância para a sociedade:

A geografia é um saber vivido e aprendido pela própria vivência. Um saber que nos põe em contato direto com nosso mundo exterior, com o seu todo e com cada um de seus elementos, a um só tempo. Se nisto reside sua peculiaridade, da qual deriva sua natural popularidade, reside nisto igualmente seu amplo significado político.

Ainda de acordo com Moreira, é importante ressaltar essa visão da Geografia enquanto ciência utilizada e vivida no cotidiano, muito mais que um conhecimento científico essa ciência é plural e intrínseca a vivência social, se materializando diariamente na ação de seus atores sociais. Segundo Lacoste (1997, p. 25):

$\mathrm{Na}$ verdade, a função ideológica essencial do discurso da geografia escolar e universitária foi, sobretudo, a de mascarar por procedimentos que não são evidentes, a utilidade prática da análise do espaço, sobretudo para a condução da guerra, como ainda para a organização do Estado e prática do poder. É, sobretudo, quando ele aparece inútil que o discurso geográfico exerce a função mistificadora mais eficaz, pois a crítica de seus objetivos neutros e inocentes parece supérflua.

Lacoste (1997), ainda afirma que durante muito tempo a Geografia foi utilizada para fazer a guerra, como estratégia militar e política de dominação, sendo utilizada para consolidar e estruturar o modo capitalista de produção e atender aos interesses da burguesia. A Guerra do Vietnã é um exemplo, uma vez que, em 1972, quando a partir de um estudo geográfico de análise espacial para verificar os melhores locais surgiu um plano de aniquilamento sistemático da rede de diques que protegem as planícies extremamente populosas do Vietnã do Norte (LACOSTE, 1997).

Diferente da Geografia Tradicional, a Geografia Crítica traz a análise geográfica enquanto oportunidade de libertação do homem. Ademais, a Geografia passa a ser práxis revolucionária com objetivo de transformar o espaço, estudando as práticas sociais e os sujeitos que compõem e constroem este espaço.

A partir dessa corrente, o espaço passa a se tornar objeto principal de estudo da Geografia, pois é nele que se pode ver a materialização da sociedade em todas as suas nuances, uma vez que o espaço é verdadeiro e amplamente social, representando as dinâmicas sociais sem menosprezar as questões naturais e suas singularidades (SOUZA, 2013).

O espaço geográfico é um dos conceitos mais importantes da Geografia, ele é analisado enquanto fenômeno social produzido na relação sociedade-natureza, é um conceito complexo exigindo um esforço de construção epistemológica devido a sua abrangência e os diversos debates teóricos acerca do tema. Segundo Santos (2012, p. 30), “o espaço não é nem uma coisa nem um sistema de coisas, senão uma realidade relacional: coisas e relações juntas". O conceito de espaço perpassa o material e se dá principalmente nas relações de trabalho da sociedade, diante disso, não pode ser considerado estático, mas dinâmico e concreto.

Segundo Carlos (2011, p.28): 
Todavia, o espaço guarda o sentido do dinamismo das necessidades e dos desejos que marcam a reprodução da sociedade em seu sentido mais amplo, a realização da vida para além da sobrevivência.

Seguindo essa perspectiva, é visível o quanto o espaço se tornou dinâmico e local da produção e reprodução social desenvolvida cotidianamente pelos atores sociais em seus modos de apropriação do espaço, de forma tanto individual quanto coletiva envolvendo espaço e tempo delimitados (CARLOS, 2011).

Santos (2008, p. 46), nos apresenta um conceito de espaço que bem caracteriza esse contexto da Geografia Crítica:

[...] algo dinâmico e unitário, onde se reúnem materialidade e ação humana. O espaço seria o conjunto indissociável de sistemas de objetos, naturais ou fabricados, e de sistemas de ações, deliberadas ou não. A cada época, novos objetos e novas ações vêm juntar-se às outras, modificando o todo, tanto formal quanto substancialmente.

Segundo este autor, o espaço é algo em movimento, vivo, sendo fruto da ação humana e uma soma do sistema de ações e objetos. Tais elementos são indissociáveis na formação do espaço. Esse conceito vem se modificando com o passar do tempo, tem sofrido alterações que se desdobram como uma expressão da sociedade em seu processo histórico e são essenciais para responder a necessidade da época.

No campo da sociologia, Castells (1984 apud GOOTDIENER, 2010 p.124) afirma:

Acredito que estamos à beira de uma catástrofe socioespacial gigantesca, mas não, como dizem os ecologistas, por causa do processo de metropolização e devastação dos recursos naturais. É porque os novos interesses dominantes e as novas revoltas sociais tendem a dissociar o espaço das organizações e o espaço da experiência,

O referido autor traz uma abordagem marxista do espaço, conceituando-o como um produto material de uma determinada formação social. Segundo Gottdiener (2010), a teoria de Castells é formada por dois pilares: a aplicação da teoria de Althusser e a teoria da produção do ambiente construído além da utilização do conceito de urbano como uma unidade espacial dentro do sistema de ambiente construído.

Ainda de acordo com Gottdiener (2015, p. 124):

O aspecto mais importante da mudança de pensamento de Castells é que, deixando de aplicar Althusser a uma teoria do espaço, ele veio a desenvolver um aspecto específico dessa teoria, ou seja, a relação entre o Estado e o espaço de assentamento.

A teoria de Castells traz os meios de produção e a força de trabalho como processos do espaço urbano, segundo o autor o urbano é uma unidade espacial da reprodução da força de trabalho.

Castells acredita que o espaço é um elemento indispensável para a análise da sociedade atual, como afirma: "ao contrário da maioria das teorias clássicas, que supõem o domínio do espaço pelo tempo, proponho a hipótese de que o espaço organiza o tempo na sociedade em rede." (CASTELLS 2012, p. 467). Nesse contexto, é notório que o espaço tem uma relação de interação com a sociedade, as tecnologias e principalmente pelo tempo enquanto fator organizado pelo espaço.

Assim como Castells (2000), Lefebvre (1976) traz uma abordagem marxista do espaço, diretamente ligada as transformações da sociedade conforme citação abaixo:

Do espaço não se pode dizer que seja um produto como qualquer outro, um objeto ou uma soma de objetos, uma coisa ou uma coleção de coisas, uma mercadoria ou 
um conjunto de mercadorias. Não se pode dizer que seja simplesmente um instrumento, o mais importante de todos os instrumentos, o pressuposto de toda produção e de todo intercâmbio. Estaria essencialmente vinculado com a reprodução das relações (sociais) de produção (LEFEBVRE, 1976, p. 34).

Portanto, Lefebvre (1976) traz uma análise marxista do espaço, mostrando uma visão de espaço ligado à prática social, de modo que este tem um papel de estruturação de uma lógica capitalista. Partindo dessa premissa, pode-se perceber que na teoria do referido autor o espaço tem natureza multifacetada, ele é a parte material, como também o social e é lócus da produção e reprodução dos atores sociais, em todas as áreas do cotidiano humano. É essencialmente um produto social.

Deste modo, Lefebvre (1991) mostra uma visão de espaço ligado à prática social, uma visão dos sujeitos como construtores desse espaço que tem um papel de estruturação de um sistema, uma lógica capitalista.

No que tange ao espaço de representação, será tomada a definição de Lefebvre (1991), que trata da tríade do espaço percebido (práticas espaciais), concebido (representações do espaço) e vivido (espaço representacional) e, diante disso, inspira a análise sobre os sujeitos em relação a produção do espaço.

A tríade percebido-concebido-vivido (em termos espaciais: práticas espaciais, representações de espaço, espaço representacional) perde toda a sua força quando é tratada como um modelo "abstrato". [...] ela (a tríade) tem sua fonte na história de um povo, assim como na história de cada indivíduo que pertence àquele povo. [...] Compreende os loci das paixões, das ações e das situações vividas e, portanto, implica em tempo. Consequentemente pode ser [...] direcional, situacional ou relacional, porque é essencialmente qualitativa, fluida e dinâmica. (LEFEBVRE,1991, p. 40-42).

A análise tridimensional do espaço percebido, concebido e vivido constitui a autoprodução da sociedade. É perceptível que esses conceitos são compostos de subjetividade, individualidade e concomitantemente de uma conjuntura social, são processos ativos. Agora vamos conceituar esses espaços em suas particularidades.

O espaço percebido é o que é relativo às práticas espaciais, pode ser apreendido por meio dos sentidos, além dos cinco sentidos estabelecidos pela ciência, ele está ligado aos elementos, aquilo que é material. O espaço tem um aspecto perceptível que pode ser apreendido por meio dos sentidos.

Em se tratando do espaço concebido, vê-se que ele está intrinsicamente ligado ao pensamento e não pode ser apreendido enquanto tal sem ter sido concebido previamente. Ele é a representação do espaço, ações ligadas ao conhecimento e ao pensamento.

No que tange ao espaço vivido, por sua vez, pode-se dizer que ele é o espaço representacional. É a experiência vivida do espaço. Ele é o conceito que expressa a cotidianidade da vida humana, é a vivência que não se consegue definir apenas teoricamente (SCHMIDT, 2012).

O espaço se tornou dinâmico e vivificado como local da produção e reprodução social desenvolvida cotidianamente pelos atores sociais em seus modos de apropriação do espaço de forma tanto individual quanto coletiva envolvendo espaço e tempo. Espaço e tempo são conceitos essenciais da vivência humana, que estão interligados no cotidiano social. Segundo Soja (1993, p.34):

Assim como o espaço, o tempo e a matéria delineiam e abrangem as qualidades essenciais do mundo físico, a espacialidade, a temporalidade e o ser social podem ser vistos como as dimensões abstratas que, em conjunto, abarcam todas as facetas da existência humana. 
De acordo com Soja (1993), a existência humana se constrói por intermédio do imaginário, simbolismo, signos e todas as práticas temporais e espaciais presentes na sociedade.

Aqui o importante é sinalizar que o pensamento crítico não se ocupa mais de representações apenas baseadas no aspecto empírico e na experimentação. Trata-se, para além disso, de expressar a vivência dos grupos sociais. Das práticas cotidianas, das iconografias e diferentes linguagens expressa no espaço. Revela, do mesmo modo, as necessidades (individuais e sociais), os desejos relacionados ao corpo e à memória (ou o inconsciente).

Trata-se do espaço como forma de pensar, como expressão da consciência coletiva e, quando necessário, como transgressão às representações dominantes. É o lócus da ação e, de origem simbólico, tem na cotidianidade sua materialidade e no poder a sua maior expressão. Para Tuan (2013, p. 15): “[...] poucas obras tentam compreender o que as pessoas sentem sobre espaço e lugar, considerar as diferentes maneiras de experienciar (sensório-motora, tátil, visual, conceitual) e interpretar espaço e lugar como imagens de sentimentos complexos [...]". Nesse sentido, entende-se que todo sujeito citadino tem uma ligação com a sua cidade, no que tange a memórias afetivas, experiências, signos, o que podemos chamar de relação de representação.

De acordo com Lefebvre (1974), é na espacialidade que se percebe a total imbricação do percebido, concebido e vivido, além de transparecer que os fenômenos socioespaciais são tanto agentes quanto produtos da reprodução do espaço. Lefebvre (1974), deduz que o espaço traduz um conjunto de diferenças, ou seja, é o lócus de coexistência da pluralidade e das simultaneidades de padrões, de maneiras de viver a vida urbana. Contudo, não descarta a idéia de que o espaço também é o lugar dos conflitos, onde a exploração subordina não apenas a classe operária como outras classes sociais.

Para tal, o espaço percebido refere-se as práticas espaciais, a materialidade dos objetos na relação com o sujeito, já o espaço concebido são as representações do espaço e seus signos concebidas pelos agentes. No que tange ao espaço vivido, trata-se do espaço representacional, as chamadas invenções mentais, o imaginário individual e coletivo.

\section{ESPAÇO E REPRESENTAÇÃO: DIFERENTES CONTRIBUIÇÕES}

Uma contribuição significativa para a compreensão do espaço se dá a partir dos estudos de Santos (1998), através do estabelecimento do conceito de formação sócio-espacial e da concepção do espaço enquanto instância da sociedade: "o espaço organizado pelo homem é como as demais estruturas sociais, uma estrutura subordinada-subordinante. E como as outras instâncias, o espaço, embora, submetido a lei da totalidade, dispõe de uma certa autonomia" (SANTOS, 1988, p.145). É importante ressaltar que Santos (1996) apresenta o espaço enquanto fator social, organizado pelo homem e parte do processo de existência e reprodução social. O autor combate a ideia arcaica de espaço enquanto vazio, sem articulação, vácuo e traz uma análise critica da realidade baseado nas transformações da globalização que levaram a um estabelecimento de novas dinâmicas relativas ao espaço.

Posteriormente, Santos (1996), em seu livro A Natureza do Espaço, traz uma nova conceituação para o espaço geográfico. Segundo o autor: "O espaço é formado por um conjunto indissociável, solidário e também contraditório, de sistemas de objetos e sistemas de ações, não considerados isoladamente, mas como o quadro único no qual a história se dá" (SANTOS, 2006, p.39). Para o autor, a natureza é que dá origem as coisas que posteriormente serão trabalhadas (transformadas) pelo homem através da técnica, por meio de uso de instrumentos e técnicas o homem constrói o espaço. E a partir da evolução das técnicas e relações sociais o espaço geográfico também sofre mudanças, o espaço seria então uma expressão da própria da sociedade. 
Ainda sobre o conceito de espaço, o geográfo britânico David Harvey tece uma crítica sobre o que chama de falta de preocupação com a conceituação de espaço pelas ciências humanas, como pode ver a seguir:

Marx, Marshall, Weber e Durkhein tinham isso em comum: davam prioridade ao tempo e à história e não ao espaço e à geografia, e, quando tratavam do espaço e da geografia, tendiam a considerá-los de modo não problemático, enquanto contexto ou sítio estável para a ação histórica. (HARVEY, 2006, p. 142).

O autor enfatiza a necessidade e importância de se discutir o conceito de espaço enquanto teoria espacial de categoria de análise e investigação. Partindo do pressuposto de que para compreender a sociedade atual é necessário observar a relação entre tempo e espaço tomando cuidado para não priorizar um em detrimento ao outro. Além disso, Harvey (2006) faz uma abordagem tripartite sobre o espaço dividindo-o em espaço absoluto, relativo e relacional em uma teoria marxista que se soma a teoria lefebvriana da representação do espaço.

\begin{abstract}
Não existiria, por exemplo, nenhum valor no espaço-tempo relacional sem trabalhos concretos construídos em inumeráveis lugares no espaço e tempo absolutos. Nem o valor emergiria como um 'poder imaterial mas objetivo' sem os inumeráveis atos de troca, os processos de circulação contínuos que mantêm o conjunto do mercado mundial no espaço-tempo relativo. O valor é, portanto, uma relação social que internaliza toda a história e a geografia do trabalho concreto no mercado mundial; expressa as relações sociais (principalmente, mas não exclusivamente, de classe) construídas pelo capitalismo na escala mundial. (HARVEY, 2012, p. 26).
\end{abstract}

De acordo com Harvey (2012), espaço absoluto é algo fixo onde acontecem planejamento de eventos ou registros, como por exemplo, cidades e condomínios fechados com espaços essencialmente cartesianos. Já o espaço relativo tem um caráter relacional de espaço-tempo inspirado nas contribuições de Albert Einstein. É o espaço do movimento, da circulação e dos fluxos. Por sua vez, o espaço relacional refere-se a relações internas, é o espaço dos sonhos, sendo inspirado em Leibniz. O autor também aborda questão da tensão dialética entre o material, concebido e vivido, articulando espaço e tempo e deixando claro o quanto esses espaços são interdependentes. Diante disso, é importante ressaltar a abordagem do espaço vivido enquanto local de produção de sensações e emoções, tendo como força analítica a tensão dialética e a interação.

Espaço e tempo são conceitos essenciais da vivência humana, que estão interligados no cotidiano social. Segundo Soja (1993, p.34):

Assim como o espaço, o tempo e a matéria delineiam e abrangem as qualidades essenciais do mundo físico. A espacialidade, a temporalidade e o ser social podem ser vistos como as dimensões abstratas que, em conjunto, abarcam todas as facetas da existência humana.

De acordo com Soja (1993), a existência humana se constrói por intermédio do imaginário, simbolismo, signos e todas as práticas temporais e espaciais presentes na sociedade.

O geógrafo francês Roger Brunet, por sua vez, traz contribuições sobre o conceito de que se assemelham a de Milton Santos no que tange a interação do homem com a natureza para criação e produção do espaço. De acordo com Brunet (2001, p. 15): 
objetos que o povoam [...] Ele nasce com o trabalho das sociedades e só tem um fim com ele.

O autor afirma que o espaço enquanto superfície é imprescindível para análise geográfica uma vez que, por intermédio dela pode-se constatar fatores como localização e distância.

Brunet foi o criador da coremática, um estudo teórico-metodológico que objetiva a representação da análise do espaço geográfico utilizando modelos gráficos, uma forma de expressão dinâmica. Segundo Brunet (2001), os homens criam Coremas ao transformarem o espaço mediante as suas relações de trabalho. Tais estruturas se materializam por uma expressão cartográfica, que o autor as considera como abstrações ou um sistema de signos.

Para entendimento dos espaços de representação será tomada a definição de Lefebvre (1991) que trata da tríade que envolve o espaço percebido (práticas espaciais), o concebido (representações do espaço) e o vivido (espaço representacional) e diante disso inspira a análise sobre os sujeitos em relação a produção do espaço, como pode-se ver abaixo:

\begin{abstract}
A tríade percebido-concebido-vivido (em termos espaciais: práticas espaciais, representações de espaço, espaço representacional) perde toda a sua força quando é tratada como um modelo "abstrato". [...] ela (a tríade) tem sua fonte na história de um povo, assim como na história de cada indivíduo que pertence àquele povo. [...] Compreende os loci das paixões, das ações e das situações vividas e, portanto, implica em tempo. Consequentemente pode ser [...] direcional, situacional ou relacional, porque é essencialmente qualitativa, fluida e dinâmica (LEFEBVRE, 1991, p. 40;42).
\end{abstract}

Para melhor exemplificação dessa relação, será utilizada a Figura 1:

Figura 1 - Tripé sobre a produção do espaço

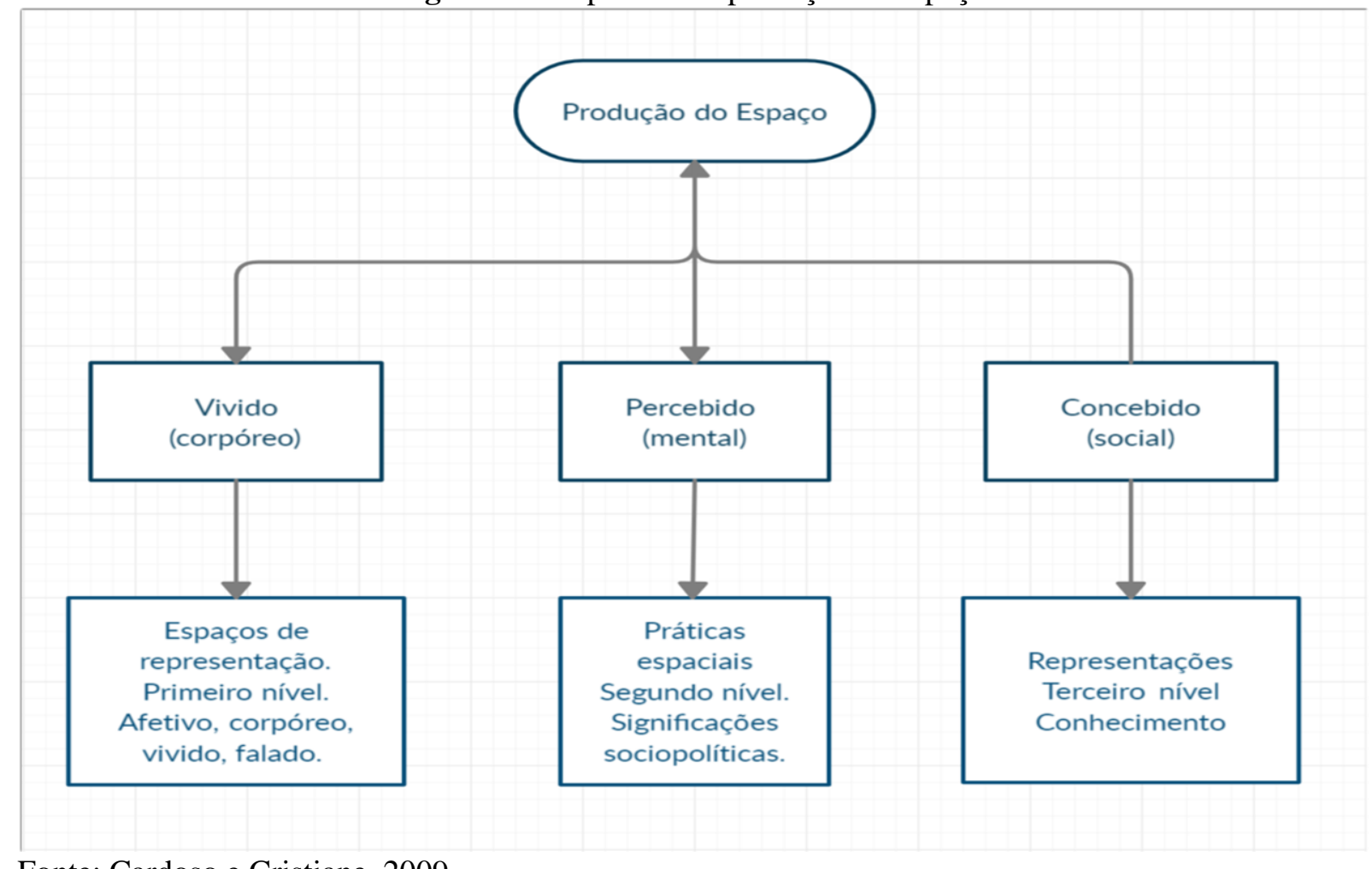

Fonte: Cardoso e Cristiane, 2009

Conforme figura acima, a análise tridimensional do espaço percebido, concebido e vivido constitui a autoprodução da sociedade. É perceptível que esses conceitos são 
compostos de subjetividade, individualidade e, concomitantemente, de uma conjuntura social como processos ativos. Partindo desse pressuposto e consoante os postulados de Schmidt (2012), serão conceituados esses espaços em suas particularidades: o espaço percebido é relativo as práticas espaciais e pode ser visto por meio dos cinco sentidos estabelecidos pela ciência. Está ligado aos elementos, aquilo que é material, sendo que o espaço tem um aspecto perceptível que pode ser apreendido por meio dos sentidos.

Ainda de acordo com Schmidt (2012), em se tratando do espaço concebido: vê-se que ele está intrinsicamente ligado ao pensamento. $\mathrm{O}$ espaço não pode ser percebido enquanto tal sem ter sido concebido previamente em pensamento, pois ele é a representação do espaço, de ações ligadas ao conhecimento. No que tange ao espaço vivido, pode-se dizer que ele é o espaço representacional, é a experiência vivida do espaço. Ele é o conceito que expressa a cotidianidade da vida humana, é a vivência que não se consegue definir apenas teoricamente.

Concomitantemente a essa proposta, Lefebvre (1983) com sua tríade do espaço de representação, trata o aspecto da representação para além da dominação, como forma de quebrar certos paradigmas

Aqui, o importante é sinalizar que o pensamento crítico não se ocupa mais de representações meio-mortas em estado de sobrevivência, entretanto que deveria surpreendêlas em sua vida, dentro da vivência e inclusive ao nascer, quando surge. De onde? Da prática. Através de que? Dos grupos sociais e da linguagem ou, mas bem das línguas, mas também das necessidades (individuais e sociais) dos desejos, do chamado ao corpo, e da memória: o "inconsciente" (LEFEBVRE, 1983).

A representação é entendida, portanto, como forma de pensar, como expressão da consciência coletiva, como o lócus da ação de origem simbólico que tem na cotidianidade sua materialidade. Todo sujeito tem uma ligação como espaço em que vive, no que tange a memórias afetivas, experiências, signos, o que se pode chamar de relação de representação. Para tal, o espaço percebido refere-se as práticas espaciais, a materialidade dos objetos na relação com o sujeito, já o espaço concebido são as representações do espaço e seus signos concebidas pelos agentes conceituais, no que tange ao espaço vivido trata-se do espaço representacional, as chamadas invenções mentais, o imaginário individual e coletivo.

Assim, é importante pensar sobre como esse espaço é produzido, de que forma se dão essas relações. Segundo a teoria de Lefebvre (1984) acontece de três maneiras: prática espacial, representações do espaço e espaços de representação, diante disso, Lefebvre (1984) faz uma análise tridimensional do espaço em sua obra como podemos ver a seguir:

\footnotetext{
A prática espacial, que engloba produção e reprodução, lugares especificados e conjuntos espaciais próprios de cada formação social, que assegura a continuidade numa relativa coesão. Essa coesão implica, no que concerne ao espaço social e a relação de cada membro de determinada sociedade ao seu espaço, ao mesmo tempo de uma competência certa e uma certa performance; as representações do espaço, ligadas às relações de produção, a "ordem" que elas impõem e, desse modo, ligadas ao conhecimentos, aos signos, aos códigos, às relações "frontais"; os espaços de representação, apresentam (com ou sem códigos) simbolismos complexos, ligados ao lado clandestino e subterrâneo da vida social, mas também a arte que eventualmente poder-se-ia definir não como código do espaço, mas como código de representação (LEFEBVRE, 1984,p.36)
}

Os espaços de representação estão imbricados a vida cotidiana dos sujeitos, diante disso, para compreensão dessa questão é necessário compreender as relações de espaço e tempo que compõem essa produção social, e tal espaço social é a expressão das normas sociais, costumes, valores construídos em um determinado ambiente. Para Lefebvre (1984), o espaço é parte do processo e produto das relações sociais, fazendo parte dos meios e forças de produção. 
Por fim, conclui-se que os espaços de representação são importantes para compreender o cotidiano humano, uma vez que envolvem as dimensões física, mental e social dos sujeitos. Partindo dessa premissa, é notório destacar a força e a importância dessa dimensão espacial para a Geografia diante do fenômeno da globalização, é necessário pensar em modelos para melhor entendimento do conceito, além de sobrepor limitações na sua interpretação.

\section{CONSIDERAÇÕES FINAIS}

Abordar o espaço geográfico segundo a corrente da Geografia Crítica é um desafio devido as diversas abordagens epistemológicas realizadas sobre o conceito. Nesses termos, é fato que o espaço geográfico é um conceito de suma importância para a Geografia, isso explica as inúmeras teorias sobre essa categoria analítica. Partindo desse pressuposto, concluise ser de extrema importância entender as implicações do espaço na sociedade, uma vez que ele é produto das relações sociais.

Ademais, reconhecer a espacialização na sociedade atual é entender todo um modo de vida e a ação dos atores sociais cotidianamente de forma muito diversificada, uma vez que o espaço se transforma conforme as mudanças na sociedade. Ele é produzido e reproduzido por ela em todas as suas nuances, tendo como foco as relações de trabalho.

Esse estudo mostra o espaço em um contexto de uma sociedade de classes subordinada a um sistema capitalista e revela o quanto as ações dessa sociedade dinamizam o espaço de forma a modificá-lo conforme suas ações. Não se tratam, portanto, de ações naturais, mas daquelas que são fruto de conflitos. Conclui-se, portanto, que o espaço geográfico é um conceito complexo e dinâmico e que deve ser amplamente discutido objetivando o avanço da ciência geográfica frente as necessidades da sociedade.

\section{REFERÊNCIAS}

BRUNET, Roger. Le déchiffrement du monde: théorie et pratique de la géographie. Paris: Belin, 2001 [1990].

CARLOS, Ana Fani Alessandri. A condição espacial. São Paulo: Contexto, 2011. 157 p.

CASTELLS, Manuel. A sociedade em rede. São Paulo: Editora Paz e Terra, 2000.

CORRÊA, Roberto Lobato. Geografia brasileira: crise e renovação. In: MOREIRA,Ruy (org). Geografia: teoria e crítica. O saber posto em questão. Petrópolis: Vozes,1982.

GOTTDIENER, Mark. A produção social do espaço urbano. 2.ed. São Paulo: Edusp, 2010.

HARVEY, David. O espaço como palavra chave. Revista GEOgraphia. V. 14, n. 28, 2012, p. $8-39,2012$. Original: HARVEY, D. Space as a keyword. In: CASTREE, N. e GREGORY, D. (Orgs.) David Harvey: a critical reader. Malden e Oxford: Blackwell, 2006. Tradução livre: Letícia Gianella. Revisão técnica: Rogério Haesbaert e Juliana Nunes.

HARVEY, David. A produção capitalista do espaço. 2. ed. São Paulo: Annablume, 2006.

LACOSTE, Yves. A Geografia isso serve, em primeiro lugar, para fazer a guerra. Trad. M. C. França. 4. ed. Campinas: Papirus, 1997.

LACOSTE, Yves. Paysages politiques. Paris:Biblio Essais, 1990. 
LEFÉBVRE, Henri. A produção do espaço (1ª ed. 1974) Paris, Anthropos, 1984.

LEFÉBVRE, Henri. Espaço y política. (1ª ed. 1973) Barcelona. Ediciones Peninsula, 1976.

LEFEBVRE, Henri. La presencia y la ausência: contribucion a la teoria de las representaciones. México, DF: Fondo de Cultura Económica, 1983

LEFEBVRE, Henri. La production de l'espace. Paris: Ed anthropos, 1974.

LEFEBVRE, Henri. O direito à cidade. $1^{\circ}$ ed. São Paulo: Moraes, 1991.

MOREIRA, Ruy. O que é geografia. 5. ed. São Paulo: Brasiliense, 1985.

SANTOS, M. Metamorfoses do Espaço Habitado: fundamentos teóricos e metodológicos da geografia. $6^{\text {a }}$ ed. São Paulo: Edusp, 2012.

SANTOS, Milton. Por Uma Geografia Nova. São Paulo: Hucitec, 1988.

SANTOS, Milton. Espaço e método. (1 $1^{\mathrm{a}}$ ed. 1985) 5ª Ed. EDUSP, São Paulo, 2008.

SANTOS, Milton. Técnica, Espaço, Tempo. (1 ${ }^{\mathrm{a}}$ ed. 1994) 5ª Ed. EDUSP, São Paulo, 2008.

SANTOS, Milton. A Natureza do Espaço. Técnica e Tempo. Razão e Emoção. $2^{\circ}$ Edição. São Paulo: Hucitec, 1996.

SCHMIDT, Christian. A teoria da produção do espaço de Henri Lefebvre: em direção a uma dialética tridimensional. Trad. Marta Inez Medeiros Marques; Marcelo Barreto.

GEOUSP - espaço e tempo, São Paulo, n. 32, p. 89-109, 2012

SOJA, Edward Willian. Geografias pós-modernas: a reafirmação do espaço na teoria social crítica. Rio de Janeiro: Jorge Zahar 1993.323 p.

SOJA, Edward Willian. Le développement des territoires: formes, lois, aménagement. La Tour D’Aigues, 2004.

SOUZA, Marcelo Lopes de. Por uma Geografia nova. São Paulo: Hucitec-Edusp, 1978.

SOUZA, Marcelo Lopes de. Os conceitos fundamentais da pesquisa sócio-espacial. Rio de Janeiro: Bertrand Brasil, 2013.

TUAN,Yi-fu. Espaço e lugar: a perspectiva da experiência. Tradução: Lívia de Oliveira. Londrina: Eduel, 2013. 